\section{EXILIO Y COMPROMISO: EL CASO DE ADOLFO SÁNCHEZ VÁZQUEZ}

\author{
Francisco José Martínez
}

UNED

\section{EXILE AND ENGAGEMENT: THE CASE OF ADOLFO SÁNCHEZ VÁZQUEZ}

\begin{abstract}
The paper analyzes the figure of Adolfo Sánchez Vázquez from the point of view of their experience of the exile as well as the reflection that on that notion carried out. Adolfo Sánchez Vázquez considered exile as an expulsion that was cutting the roots of the exile to their homeland. Adolfo Sánchez Vázquez has maintained a constant commitment to the ideals that led him intro exile adapting to changing circumstances but not renege on them according to their interpretation of marxims as a philosophy of praxis and a new praxis of the philosophy.
\end{abstract}

KEY WORDS: Adolfo Sánchez Vázquez; exile; uprooting of the mother country; ideals; marxims; philosophy of praxis; praxis of the philosophy.

\begin{abstract}
RESUMEN: Adolfo Sánchez Vázquez consideró el exilio como un destierro que cortaba las raíces de los exiliados con su tierra. Adolfo Sánchez Vázquez ha mantenido un compromiso constante con los ideales que le llevaron al destierro adaptándolos a las circunstancias cambiantes pero sin renegar de ellos de acuerdo con su interpretación del marxismo como una filosofía de la praxis y una nueva praxis de la filosofía.
\end{abstract}

PALABRAS CLAVE: Adolfo Sánchez Vázquez; exilio; desarraigo; ideales políticos; marxismo; filosofía de la praxis; praxis de la filosofía.

"El exilio es un desgarrón que no acaba de desgarrarse, una herida que no cicatriza, una puerta que parece abrirse y que nunca se abre."

"Siempre en vilo, sin tocar tierra. El desterrado, al perder su tierra, se queda aterrado (sin tierra) - El destierro no es un simple trasplante de una tierra a otra; es no sólo la pérdida de la tierra propia, sino con ello la pérdida de la tierra como raíz o centro."

"Lo decisivo es ser fiel -aquí o allí- a aquello por lo que un día se fue arrojado al exilio. Lo decisivo no es estar-acá o allá- sino cómo se está."

\section{EL EXILIO COMO CONDICIÓN ONTOLÓGICA DEL SER HUMANO}

Se ha podido decir que la condición ontológica del hombre es la del éxodo y el exilio. El mito de la expulsión del paraíso alude a este mal acomodo que el hombre encuentra en el mundo. Su condición de animal extraño, de mono enfermo como decía Unamuno, hace que lejos de adaptarse sin problemas al entorno natural, el hombre transforme dicho medio natural no sólo para vivir sino para vivir bien. La necesidad constitutiva que la cultura tiene para el hombre expresa claramente que la naturaleza no le basta.

\section{El EXILIO COMO RASGO PERMANENTE DE LA HISTORIA ESPAÑOLA}

Si bien todo hombre es de forma radical un exilado, hay naciones en las que el exilio es uno de sus rasgos constitu- 
yentes. Naciones que en lugar de ser tierras de acogida son tierras de rechazo. Del rechazo del extraño y también de rechazo del autóctono que no se adecua a los estándares habituales. Hay culturas y naciones que sólo se pueden constituir de forma monolítica sometiendo o expulsando al diferente. Dentro de estas naciones excluyentes ocupa un lugar privilegiado la nuestra. España se forjó como nación derrotando a los árabes andalusies y expulsando a los moriscos, se consolidó expulsando a los moriscos y persiguiendo a los luteranos y demás herejes. Hizo la vida imposible a los ilustrados, expulsó a los afrancesados como Goya, obligó al exilio a los liberales', luego a los republicanos y por fin a los disidentes internos ya en los años sesenta y setenta del siglo XX. Pero entre todos estos exilios ocupa un lugar preferente por su carácter masivo y plural el exilio de los republicanos españoles tras la victoria de las tropas rebeldes del general Franco auxiliadas por los nazis y fascistas y toleradas por las democracias europeas.

Como el propio Sánchez Vázquez destaca, el exilio republicano de 1939 fue de carácter político debido a la derrota del ejército republicano por los sublevados con el apoyo nazi y fascista; masivo, pues no sólo afectó a la élite política y cultural sino a miles de trabajadores y gente del pueblo; y fiel reflejo de la composición de los defensores de la república en el sentido territorial, social y profesional, ya que abarcaba a individuos de todas las tierras de España, así como de todas las clases sociales y de todas las profesiones ${ }^{2}$. El exilio mexicano del 39 presentaba un amplio espectro político que abarcaba desde los republicanos liberales hasta socialistas, comunistas y anarquistas, pasando por los nacionalistas vascos y catalanes. Por su composición profesional los integrantes de dicho exilio tenían todas las profesiones aunque predominaban las más cualificadas en los campos de la cultura, la política, las ciencias, la literatura, la filosofia y las artes plásticas. Entre ellos destacaban numerosos profesores universitarios de gran valía intelectual. Otra especificidad de este exilio fue su larga duración, ya que al contrario de los exilios del siglo XIX, el que siguió a la guerra civil duró casi 40 años. Por otra parte, y aunque la mayoría de los exiliados, al menos hasta el fin de la Segunda Guerra Mundial albergaban la esperanza de un pronto regreso a una patria democrática, esperanzas que se ensombrecieron cuando la guerra fría consolidó el régimen de Franco, todos ellos se fueron integrando en su pais de acogida y contribuyeron con su aportación cultural y profesional al desarrollo de México ${ }^{3}$.
Dentro de este exilio republicano masivo vamos a centrarnos en la figura de Adolfo Sánchez Vázquez no sólo porque fuera un exiliado, sino también porque ha dedicado muchos de sus trabajos, tanto literarios como filosóficos, a reflexionar sobre el hecho atroz del exilio. Adolfo no sólo ha padecido el exilio sino que lo ha pensado y por ello ocupa un lugar excepcional dentro del exilio español de 1939.

La experiencia esencial del exilio como constante de la historia española imposibilita una fundamentación del patriotismo en la historia, ya que no hay una historia compartida porque lo que unos recuerdan como victorias los otros lo sufren como derrota y humillación. No sólo desde el punto de vista de los nacionalismos periféricos que discuten la concepción castellanocéntrica de la historia española sino también desde las tradiciones que una y otra vez han sido marginadas y puestas en la difícil tesitura de elegir entre la asimilación o el exilio se rechaza la idea de una historia común. Una historia en la que todos nos podamos reconocer y cuyas conmemoraciones fundamentales pudieran ser integradoras y no supusieran la exclusión de partes esenciales de la población. En ese sentido y siguiendo la noción de "patriotismo constitucional' de Habermas (tan mal interpretada, por otra parte) la fundamentación del patriotismo no puede hacerse mediante el recurso a una historia común, pero tampoco basándose en una continuidad jurídica ya que la instauración de la democracia exige romper con la legalidad vigente antidemocrática, ni tampoco mediante el recurso a la fundamentación económica que supone la economía capitalistas, como los cristianodemócratas y la línea mayoritaria de los socialdemócratas hicieron en los comienzos de la República Federal Alemana. Debido a estas imposibilidades la única fundamentación del patriotismo que puede ser compartida por todos es la que se basa en los procedimientos formales de la democracia y en los valores que impregnan dicha democracia y que son los contenidos en las diversas declaraciones de derechos humanos. La fundamentación esencial del patriotismo tendría que ser la idea de que nuestra patria es un sistema democrático avanzado en el que se respetan los derechos humanos y que los hace respetar en las relaciones internacionales en las que se encuentra inmersa y no una historia que ha sido en su mayor parte una historia de exclusiones, asimilaciones forzosas y expulsiones de todos los que no se ajustaban a la norma mayoritaria, ni tampoco el hecho de que sea una nación rica y poderosa que cuente, aunque sea en un papel subsidiario y sometido a los gran- 
des, en la arena mundial. Es verdad que esta justificación del patriotismo no es muy motivante a nivel afectivo, pero en un país tan caliente y exaltado como el nuestro esta frialdad podría ser una virtud más que un defecto.

\section{El exillo de Adolfo Sánchez Vázouez}

A principios del año 1939 ASV estaba en Cataluña como comisario político en el $5 .^{\circ}$ Cuerpo de Ejército a las órdenes de Lister y del entrañable Santiago Álvarez y era el responsable del periódico Acero que se publicó hasta el día mismo en que recibieron la orden de atravesar la frontera el 9 de febrero. Entre las misiones que cumplió en estos tiempos Adolfo se encontraba el llevar alimentos a Antonio Machado y su madre que estaban cerca ya de la frontera.

La última misión de $\mathrm{ASV}^{4}$, que llevó a cabo precisamente con Santiago Álvarez, fue atravesar los Pirineos hacia Perpignan para convencer al general Rojo de que se dirigiera hacia el centro para reunirse con Negrín y mantener la lucha lo más posible. Pero la sublevación traidora de Casado impidió esta maniobra. Entonces ASV y Santiago Álvarez se dirigieron desde Perpignan a París el 4 de marzo y allí al confirmarse la revuelta de Casado se considera que la misión de dirigirse a Toulouse para convencer al general Rojo no tiene sentido. Adolfo se queda en un albergue que la Asociación de Escritores Franceses había preparado cerca de París, donde se reúne con su amigo Juan Rejano y encuentran alli algunos escritores catalanes como Pere Quart, Mercé Rodoreda y Sebastián Guasch. Allí les Ilega la noticia de que el general Cárdenas, presidente de México, había hecho la oferta de acoger a los exiliados españoles y Adolfo a propuesta del PCE ${ }^{5}$ es admitido como viajero en el primer barco que saldria del puerto francés de Séte, el Sinaia. La que luego sería su esposa, Aurora Rebolledo, llegaría a México en el tercer barco fletado por Cárdenas para recoger a los exilados españoles, el Mexique.

Adolfo fue en el Sinaia con Juan Rejano y con Pedro Garfias que en la travesía compuso el poema "Entre España y México" en el que se puede leer 6 :

Como en otro tiempo por la mar salada

Se va un río español de sangre roja,

De generosa sangre desbordada...
Pero eres tú, esta vez, quien nos conquista

Y para siempre, joh vieja y nueva España!

El 13 de junio de 1939 llegan al puerto de Veracruz donde son acogidos por una multitud y recibidos por el secretario de Gobernación y el secretario de la poderosa Confederación de Trabajadores de México, Vicente Lombardo Toledano, "estrenando de esta manera una nueva e incierta vida: la del exilio"7.

La acogida de México a los exiliados españoles fue muy cordial, aplicando ese derecho de asilo del que siempre la nación mexicana ha hecho gala hasta nuestros días. El derecho de asilo, en tanto que "derecho a acogerse a la protección de un país ajeno cuando en el propio se es perseguido", supone la afirmación de la libertad en un doble sentido: en primer lugar, el asilo permite que el acogido obtenga la libertad que se le niega en su propio pais, $y$, en segundo lugar, al acogerlo, el país que recibe al exiliado reafirma su libertad y su independencia en el concierto de las naciones. Lo que el derecho de asilo protege no son tanto unas determinadas opiniones o posiciones políticas, sino el derecho del individuo a tenerlas y defenderlas ${ }^{8}$.

Desde el primer momento ASV orientó su vida en México, por un lado, hacia la cultura, participando en la fundación y organización de numerosas revistas y agrupaciones de intelectuales (Romance, España Peregrina, Ultramar, la Unión de Intelectuales Españoles en México, etc.) y, por otro, hacia la política, donde llegó a ocupar puestos dirigentes en la numerosa e insigne agrupación mexicana del PCE. En 1941 ASV se traslada a Morelia donde da clases de Filosofía y se casa con Aurora. Vuelve a la capital y tras numerosos trabajos reanuda sus estudios universitarios en la Facultad de Filosofía y Letras de la UNAM. La actividad política y la necesidad de sobrevivir le vuelven a alejar de la universidad hasta que vuelve a ella en los años cincuenta para estudiar filosofía. En ese tiempo la filosofía alemana y el magisterio de profesores españoles exiliados como José Gaos o Eduardo Nicol eran dominantes. Sólo Eli de Gortari enseñaba marxismo y con él ASV empezó su carrera universitaria como ayudante en 1952. En 1955 consigue ASV su Maestría en Filosofía con el trabajo "Conciencia y realidad en la obra de arte" En 1954 se produjo un enfrentamiento entre la Agrupación mexicana del PCE y el representante del Comité Central que se saldó en 1957 con la venida de ASV a París a discutir con Claudín como 
representante del Comité Central del Partido. La rígida aplicación del centralismo democrático supuso la sumisión de la instancia local al órgano superior y condujo a nuestro filósofo a abandonar sus responsabilidades políticas en el Partido y mantenerse como simple militante de base. Aprovechando este viaje a Europa Adolfo pudo ver en Biarritz a su padre y a sus hermanos a los que no veía desde hacía casi veinte años. Desde 1959 ASV fue nombrado profesor a tiempo completo de la UNAM, lo que le permitió escribir sus primeras contribuciones al campo de la estética desde el punto de vista marxista, Las ideas estéticas de Marx (1965) y su monumental Filosofía de la praxis (1967 y 1980) reeditada recientemente en México con un prólogo del que suscribe. A partir de entonces la labor docente e investigadora de ASV es incesante en los campos de la estética, la filosofía política, la ética y el análisis de los países del llamado socialismo real desde un punto de vista original que hace hincapié en el concepto nuclear de praxis y que se inspira en los principios del humanismo marxista, presente en los Manuscritos de 1844. Para ASV el marxismo es una praxis que conjuga una teoria que pretende conocer la realidad, un proyecto de emancipación individual y social, una crítica de la existente sociedad capitalista y una práctica revolucionaria ${ }^{9}$.

\section{VivenCia poÉtica del exilio como destierRo EN ASV}

Pero como ya hemos dicho anteriormente ASV no es sólo un exiliado sino alguien que ha reflexionado sobre el exilio durante muchos años en confrontación con la noción de "transterrado" de su maestro Gaos a la que él oponía simplemente la de desterrado. Esta reflexión se lleva a cabo en dos vertientes, una poética a través de una serie de sonetos que tratan la vivencia del exilio y la otra teórica en diversos trabajos filosóficos. Comencemos por el tratamiento poético que Adolfo lleva a cabo en varios sonetos escritos a la llegada a México. Son catorce sonetos que ASV denomina "Sonetos del destierro" y que considera, al contrario que los contenidos en su libro anterior El pulso ardiendo, "más quevedescos que gongorinos", más claros y menos herméticos que los anteriores ${ }^{10}$. En estos sonetos ASV piensa y siente el exilio como un destierro, como un desarraigo, como una obsesión por una vuelta que va quedando poco a poco postergada.
En el soneto titulado "El desterrado" se muestra el exiliado como aquel al que "el hacha lo dejó sin fundamento" y que, por lo tanto, permanece "sin raíz, ni cimiento, desterrado". En el soneto titulado "Al dolor del destierro condenados" dado que se ha perdido la raíz en la tierra "el destierro se torna fundamento". El desterrado en lugar de tener su arraigo y fundamento en la tierra originaria, al perder ésta no tiene más fundamento que el propio destierro, es decir la falta misma de la tierra. En el soneto "Tierra de dolor" tras evocar la sangre y la muerte que han asolado el solar patrio se dice a la muerte en figura de labrador que no espere cosechar nada en "quien sabe encontrar a borbotones/en el terrón más duro, su consuelo". En el poema titulado "Yo sé esperar" el autor exclama:
"prefiero que el recuerdo me alimente, conservar el sentido con paciencia y no dar lo que busco por hallado
que el pasado no pasa enteramente y el que olvida su paso, su presencia, desterrado no está, sino enterrado".

El tiempo del destierro es un tiempo anímico que sólo contabiliza adecuadamente el "Reloj del alma". Título de otro soneto que concluye de esta manera:

\footnotetext{
"tomando por medida su ventura, por cuadrante un dolor interminable, se mediría el tiempo desmedido."
}

Los dos últimos sonetos a los que vamos a aludir los transcribimos en su integridad ya que condensan esta postura sobre el exilio que dominaba en el alma de Adolfo en estos primeros años de destierro.

"La tierra que pisamos"

Cuando vivo el destierro, la mudanza de ser en esta tierra un peregrino, y el corazón incita en el camino a encontrar una tregua en esta andanza;

cuando siento que el alma no descansa aunque el cuerpo desdiga su destino, y el andar se convierte en duro sino cuyo norte es sólo la esperanza, 
comprendo que mi vida está fundada en no afirmar las plantas en el suelo donde tengo la vida trasplantada.

¡Oh tierra que me ofreces tu consuelo!; dejándome seguir mi derrotero, más cerca estoy de ti, más prisionero."

El destierro convierte al exilado en peregrino sometido a una andanza sin fin, que no puede afirmar las plantas en el suelo extraño en el que vive.

"Desterrado muerto"

"En la huesa ya has dado con tu empeño.

¡Cuánta furia se queda sin batalla!

Enmudece la sangre; el pecho calla

y tu dolor cabalga ya sin dueño.

La tierra es tu mansión: la sepultura,

el albergue final de la jornada.

Por testamento dejas tu pisada,

la dulce huella de tu mano pura.

El destierro no para con tu muerte que, implacable, dilata tu destino, bajo la misma tierra prolongado.

Tú no descansas, no, con esta suerte,

de muerte enajenada; con el sino

de estar bajo la tierra desterrado".

Ni siquiera con al muerte acaba el destierro, ya que éste se prolonga bajo la tierra, debido a que la muerte en tierra extraña es una muerte enajenada que mantiene el destierro incluso debajo de la tierra ${ }^{11}$.

\section{Reflexiones teóricas de ASV sobre el eXILIO}

Para ASV los rasgos principales del exilio español republicano de 1939 en México fueron: el afrontar la adversidad con una gran entereza moral, el no considerarse vencidos moralmente sino superiores a sus vencedores en el campo de batalla; por otra parte, su espíritu colectivo que se sobrepuso al juego de los intereses personales; también el esfuerzo pos superar todo sectarismo y todo espíritu de fracción y, por último, la preocupación por vincularse de forma responsable, ya antes de pisar tierra, con el gobierno y el pueblo que los acoge $e^{12}$.

Este exilio mexicano ha tenido una triple significación, política, moral y cultural. Desde el punto de vista político y a pesar del divisionismo que pronto estalló entre los diversos grupos y partidos políticos, todos los exilados mantuvieron vigentes los valores por los que habían luchado en España: la libertad, la democracia y la independencia nacional. De hecho, hasta que surgió en el interior de España una contestación política a la dictadura, la actividad de los exiliados españoles fue la única actividad política libre que se hizo en el ámbito español. Desde el punto de vista moral los exiliados siempre sintieron su superioridad moral sobre sus vencedores y se sintieron abandonados por las potencias occidentales que contemporizaron con la dictadura franquista tras la Segunda Guerra Mundial. Desde el punto de vista cultural ya León Felipe en un poema dijo que los exiliados se habian llevado consigo la canción:

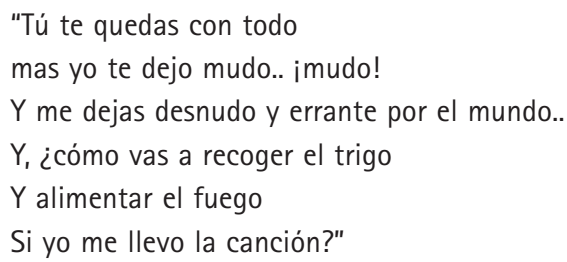

$Y$ en efecto, durante largos años la cultura española fue la cultura del exilio que no rompió con el alto nivel alcanzado en los años de la República. Sólo a finales de los cincuenta, en 1958, en el prólogo a las poesías de Ángela Figueras, el propio León Felipe se retracta de su afirmación anterior y dice "ahora también son vuestros el salmo y la canción". Pero han tenido que pasar veinte años para que se restableciera una cierta continuidad cultural que, sólo alcanzó su plenitud con el advenimiento de la democracia a finales de los años setenta. Por ello es claro que, contra lo que algunos exponentes de la derecha intentan defender actualmente, la continuidad tanto política como cultural en la que se inserta la actual democracia española es la de la República española que a pesar de sus defectos fue una democracia y en la que la cultura española alcanzó un nivel nunca igualado y no la del franquismo que fue un dictadura liberticida en la que la cultura estuvo amordazada hasta el último momento ${ }^{13}$. 
Donde Adolfo resume, además con alto nivel literario, su posición sobre el exilio como destierro es en su escrito de 1977, "Fin del exilio y exilio del fin"14 titulado anteriormente "Cuando el exilio permanece y dura". Las primeras palabras concuerdan con la visión de la historia de España que estamos dando en este escrito: "Larga es la tradición del exilio en los pueblos de lengua española. Tan larga como sus luchas por un porvenir que todavía no se hace presente". Para nuestro autor no hay ningún exilio dorado, y mucho menos autoexilio. El exilio siempre es obligado ya que la alternativa es la prisión o la muerte. Pero el exilio sigue siendo una prisión y el exiliado tiene siempre ante sí un alto muro que no puede saltar. El exilio es prisión y también es muerte, una muerte lenta que se aviva en los entierros de los otros exiliados que ya nunca podrán volver a la patria. "El exilio es un desgarrón que no acaba de desgarrarse, una herida que no cicatriza, una puerta que parece abrirse y que nunca se abre. El exiliado vive siempre escindido: de los suyos, de su tierra, de su pasado. $Y$ a hombros de una contradicción permanente: entre una aspiración a volver y la imposibilidad de realizarla ${ }^{15 " . ~ E l ~}$ exiliado está siempre en el aire, no se puede asentar ni aquí ni allá. "Siempre en vilo, sin tocar tierra. El desterrado, al perder su tierra, se queda aterrado (sin tierra) - El destierro no es un simple trasplante de una tierra a otra; es no sólo la pérdida de la tierra propia, sino con ello la pérdida de la tierra como raíz o centro"16.

El exilado no tiene tierra, como decía uno de los sonetos comentados anteriormente, sólo tiene al propio destierro por fundamento. El destierro no sólo supone la pérdida de la propia tierra, sino que imposibilita el aterrizaje en cualquier otra y así, el exiliado queda en el aire sobrevolando la tierra, sin raíz y sin centro, esencialmente descentrado y excéntrico. Esta sensación de pérdida hace que el exiliado no pueda vivir en su presente sino que se encuentra atrapado en el incesante ir y venir entre el pasado perdido y un futuro (imposible) en el que pudiera recuperar dicho pasado, que por otra parte, si alguna vez lo logra, ya no sería el mismo, como pueden comprobar los exiliados que regresan a su tierra tras largos años de ausencia. El exiliado se encuentra dominado por la nostalgia que le lleva a idealizar lo perdido y por ello cuando vuelve no se reconoce en su ese pasado ya perdido y que quizás nunca fue presente sino una mera idealización retrospectiva. Los exilios de larga duración van amainando poco a poco esta tensión desgarradora; a pesar de todo se van echando raíces en el lugar de acogida y cuando, por fin, se puede volver, otra decisión dramática se impone al exiliado: la de tener que elegir entre su presente en la tierra que lo ha acogido y un futuro incierto en la tierra que lo expulsó: "Y entonces el exiliado descubre con estupor primero, con dolor después, con cierta ironía más tarde, en el momento mismo en que objetivamente ha terminado su exilio, que el tiempo no ha pasado impunemente, y que tanto si vuelve como si no vuelve, jamás dejará de ser un exiliado"17. La tragedia se cierra con la conclusión de que el exiliado nunca puede dejar de serlo, ya permanezca donde está o vuelva a donde salió. Su condición de exiliado no es eliminable y le acompañara siempre, hasta la tumba y después de ella incluso. La conclusión sabia, serena de Adolfo es que, dada esta condición ineliminable que el exilio ha impreso en el alma y el cuerpo del exiliado, lo importante, "lo decisivo es ser fiel -aquí o allí- a aquello por lo que un día se fue arrojado al exilio. Lo decisivo no es estar -acá o allá- sino cómo se están"18.

ASV desde esta posición que entiende el exilio como destierro se opone a la idea de transtierro de Gaos, según la cual el exiliado no es un des-terrado o un a-terrado en el sentido de alguien que se ha quedado sin tierra sino alguien que se ha visto trasplantado a una nueva tierra en la cual además encuentra los valores de la patria perdida. En la patria de adopción reencuentra los valores que en su patria de origen actualmente están perdidos. El transterrado puede echar de nuevo raíces en América gracias precisamente a lo que de español hay en dicha América. En esta América el exilado transterrrado encuentra trasplantada o prolongada su España, la que ya no existe a este lado del Atlántico ${ }^{19}$. Posteriormente, ya en el año 2000 parece ASV abrirse a la idea de transtierro y sin negar su destierro empieza a admitir cierto transtierro, basado precisamente en el transcurrir de los años y en la inserción vital profesional y familiar en la patria de acogida, ese México al que siempre Adolfo ha tributado un respeto y una admiración y reconocimiento por la generosidad con la que trata los exiliados del 1939 especialmente a él mismo y así Adolfo concluye diciendo:

"Hemos visto que, durante los primeros años sobre todo, el exilio sólo existió y se vivió como destierro. Pero el exilio duró casi 40 años, tiempo más que suficiente no sólo para enterrar a casi todos los exiliados, sino también para acabar en los que sobrevivían con la perspectiva siempre 
anhelada de la vuelta. La posibilidad real de volver llegaba demasiado tarde. Con el tiempo, el desarraigo había dejado paso a nuevas raíces, a la integración del exiliado en la tierra que le acogió, compartiendo en ella las alegrías y sufrimientos de su pueblo, sin renunciar por ello a los ideales por los que un día se vio arrojado al exilio. En suma, el destierro se convierte, sin dejar de ser totalmente tal, en transtierro"20.

La integración en la vida mexicana no pudo hacer olvidar a los exiliados su destierro y así Adolfo no aceptaba la idea de su maestro Gaos de que más que de un destierro se trataba de un transtierro, en el sentido de que se aceptaba la continuidad entre la patria de origen y la patria de acogida. Más aún, se pensaba que la patria de acogida era la verdadera patria, ya que en ella florecian los valores que, en cambio, se negaban en al patria de origen. Esta especificidad del exilio mexicano, y en general del exilio en América latina, se basaba en una idea de España y de la Hispanidad que aunque no se identificaba con la ideología neocolonialista de la Hispanidad que cultivaba el franquismo, sí aceptaba la idea de una continuidad esencial entre España y sus excolonias en las que se destacaba precisamente su carácter español. Desde Vives y Las Casas hasta Antonio Machado se dibujaba una tradición española que no coincidía con la imperial y eterna, que era incluso su contraria, pero que no era menos española que la dominante. Gaos, Xirau y otros filósofos españoles contraponían una España quijotesca, espiritual, humanista que se separa de la Modernidad europea y se proyecta en América, a la imperial e inquisitorial que asimila a sangre y fuego el nuevo continente. Para Gaos, como nos recuerda ASV, "España es la última colonia de sí misma que queda por hacerse independiente, no sólo espiritual, sino también políticamente"21. Sólo para los intolerantes se puede hablar de dos España antagónicas, una de las cuales no es España. La reivindicación de varias tradiciones hispánicas, más o menos subterráneas, que se oponen a la dominante es esencial para poder desarrollar una idea de España amplia y que incluya a sus disidentes. De todas formas, y la reciente polémica en torno a la cuestión de la memoria histórica, lo ha vuelto a poner de relieve, la España tradicional, dominante, se resiste a admitir la igualdad de derechos de las tradiciones que su propia tradición dominante ha contribuido a destruir o asimilar de forma forzosa. Para ASV, esta interpretación era ciega para el legado prehispánico, indígena, que era un sustrato fundamental en los países hispanoamericanos en general y especialmente en México donde el indigenismo estaba muy desarrollado. De todas formas hay que reconocer que el propio Gaos, aunque por una parte recalcaba la continuidad entre España e Hispanoamérica, por otro se ocupó muy pronto de la especificidad de lo mexicano, impulsando los estudios en torno a la filosofía hispanoamericana y especialmente mexicana. Por su parte, otro exilado español, catalán, Eduardo Nicol, tampoco compartía la visión castellanocéntrica que de la historia de España tenían la mayoría de los exiliados. Por todo esto, ASV puede decir que aunque no hay que celebrar el quinto centenario de la conquista de América, dado el carácter destructivo que tiene para las culturas autóctonas indígenas, si conviene recordarlo para valorar las distintas raices que han dado lugar a la actual Hispanoamérica.

\section{EXILIO Y FILOSOFÍA}

Sánchez Vázquez, tras su primera respuesta emotiva y poética al fenómeno del exilio como destierro, reflexiona sobre el exilio desde la filosofía, como filósofo y por ello concede mucha importancia al exilio filosófico en México que fue de primera magnitud ya que numerosos profesores de las Universidades de Madrid y de Barcelona hallaron acogida parcial o total en México. De Madrid, Ilegaron José Gaos, María Zambrano, José Gallegos Rocafull y Luis Recasens Siches; de Barcelona llegaron Joaquín Xirau, Jaime Serra Hunter, Juan David García Bacca y Eduardo Nicol. Por último, ramón Xirau y el propio Sánchez Vázquez completaron su formación en tierras mexicanas. Los rasgos comunes a estos exiliados era el predominio en ellos de la filosofía alemana de los años veinte y treinta. La fenomenología, la axiología de Scheler, el historicismo y la ontología existencial heideggeriana, así como una común referencia al magisterio de Ortega, eran los principales referentes teóricos de estos filósofos exiliados. Frente a estas influencias, los exiliados tenían menos relación con el neopositivismo o con el marxismo. Todos ellos eran contrarios a la ideología del nacional-catolicismo franquista y se adherian al liberalismo democrático burgués que habia encarnado la Segunda República, aunque no tuvieron una actividad política directa. Las aportaciones principales de este granado grupo de filósofos españoles a la filosofía mexicana fue, en primer lugar, la docencia, en segundo 
lugar, la traducción, además la participación en numerosas instituciones culturales y revistas que contribuyeron a elevar el nivel cultural del país de recepción y, por último, su propia obra que para la mayor parte de ellos se desarrolló en México siendo a la par que un capítulo esencial de la filosofía española contemporánea una parte fundamental de la propia filosofía mexicana ${ }^{22}$.

ASV ha evaluado la labor de sus maestros y colegas en la Universidad mexicana a través de su participación en los numerosos actos de homenaje que la Universidad mexicana realizaba continuamente como reconocimiento a la labor de los exiliados españoles. Y asi en sus libros encontramos homenajes a Wenceslao Roces, Eduardo Nicol y Joaquín Xirau en los que destaca su concepción del exilio y su reconocimiento a la patria de adopción en la que reviven los ideales perdidos en la patria de origen. De Nicol, que fue profesor suyo, recoge las aportaciones de su libro El problema de la filosofía hispánica (1961) según las cuales "la España libre se encuentra en América". El profesor catalán que unió de forma decisiva vida y filosofia ${ }^{23}$ rechazando cualquier subjetivismo y cualquier personalismo no admitía que se pudiera ser pesimista existencial en un momento, los años sesenta, en los que la esperanza renacía en América latina. Nicol defiende la necesidad para España de una filosofía como ciencia rigurosa, capaz de elevar el pensamiento a lo universal y expresada en un estilo que no hiciera concesiones a las idiosincrasias personales y a los tipismos del lugar24.

Respecto a Joaquín Xirau, que murió de forma prematura, Adolfo además de resaltar su monumental libro Amor y mundo, retoma el rescate que el profesor catalán llevó a cabo del humanismo hispánico en la figura de Juan Luis Vives, un humanismo que se prolonga en América a través de la obra de Bartolomé de las Casas y Vasco de Quiroga ${ }^{25}$.

\section{Conclusión: Exilio Y COMPROMISO}

Como hemos visto, el exilio español del 39 fue un exilio que expulsó del país a lo mejor de la intelectualidad española, precisamente a aquella que había hecho del compromiso con la República y sus ideales de igualdad, libertad y so- lidaridad sus valores rectores. Ese exilio no fue estéril ya que, por un lado, contribuyó a mantener viva y pujante la cultura española, tan perseguida y destruida en la patria de origen, y además fue una semilla fecunda que engrandeció la cultura de los paises americanos de acogida a través de la docencia y la investigación de tantos y tantos profesores universitarios trasplantados a dichos países. Ejemplo insigne de este exilio es el de Adolfo Sánchez Vázquez que se exilia en virtud de su compromiso militante con la causa de la república y en tierra mexicana concluye su formación y desarrolla una intensa labor cultural y política que abarca como hemos visto numerosos campos, desde la poesía hasta la estética pasando por la filosofía marxista y el análisis de los países del socialismo real. Adolfo ha sido un puente fecundo entre España e Hispanoamérica en los últimos 40 años; sirviendo aquí como referente de unas concepciones estéticas, éticas y políticas creativas desde un marxismo humanista antidogmático y dialogante; y convirtiéndose en México en un embajador permanente no sólo de la cultura española sino también de los ideales éticos y políticos que encarnaba la República española y que sólo la restauración de la democracia permitió que pudieran ser asumidos de nuevo en la España peninsular.

Como conclusión transcribimos aquí un colofón de la posición de Adolfo que resume su compromiso, adaptándolo a las nuevas realidades pero sin renegar de sus ideales:

"Muchas verdades se han venido a tierra; ciertos objetivos no han resistido el contraste con la realidad y algunas esperanzas se han desvanecido. $Y$, sin embargo, hoy estoy más convencido que nunca de que el socialismo -vinculado con esas verdades y con esos objetivos y esperanzas- sigue siendo una alternativa necesaria, deseable y posible. Sigo convencido asimismo de que el marxismo -no obstante lo que en él hay que criticarse 0 abandonarse- sigue siendo la teoría más fecunda para quines están convencidos de la necesidad de transformar el mundo en el que se genera hoy como ayer no sólo la explotación y la opresión de los hombres y los pueblos, sino también un riesgo mortal para la supervivencia de la humanidad. $Y$ aunque en el camino para transformar ese mundo presente hay retrocesos, obstáculos y sufrimientos que, en nuestros años juveniles, no sospechábamos, nuestra meta sigue siendo ese otro mundo que, desde nuestra juventud, hemos anhelado". 
14 Ahora en EM, 35-38 y en TD, 569572.

1 Sánchez Vázquez destaca que en los siglos XIX y XX el exilio en España "tiene siempre un tinte liberal" (Cf., "Del exilio español en México" en EM, 68).

2 Cf. "Del destierro al transtierro".

3 Cf. ASV, "Del exilio español en México", en EM, 69-77.

4 Cf. Ana Lucas, "Adolfo Sánchez Vázquez: vida y obra", en EPF, 231-232 y ASV "Vida y filosofía. Postscriptum político-filosófico" en EM, 52-53.

5 Cf. ASV, "Testimonio del exilio de un intelectual español en México", entrevista con Paloma Ulacia y James Valender, en EM, 201-202.

6 ASV, "Vida y filosofía", EM, 53-54.

7 ASV, "Vida y Filosofías, EM, 54.

8 Cf. ASV, "Discurso sobre las libertades públicas y el derecho de asilo", en EM, 85.

9 Cf. ASV, "Marxismo y praxis" (1977) en TD, 420-426 y CEF, 55-56.

10 La poesia de ASV se encuentra recopilada en Poesía, FCE, México, 2005. Hay una edición faccsimil de su principal obra El pulso ardiendo, Centro de Ediciones de la Diputación de Málaga, Málaga, 2004.

11 ASV comenta estos poemas entre otros en "La poesía" primera de las cinco conferencias dictadas en al Facultad de Filosofia y letras de la UNAM los dias 21, 23,24,29 y 30 de noviembre de 2005 en el marco de la Cátedra Extraordinaria Maestros del Exilio Español que están editadas en CEFP, 2-23.Cf. igualmente "Mi trato con la poesía en el exilio"(1993) ahora en TD, 580-589.

12 Cf. ASV, "Recordando al Sinaia", en EM,23-24.

13 Cf. ASV, "Palabras al develarse la placa conmemorativa del cincuenta ani-

Recibido: 20 de octubre de 2008 Aceptado: 23 de abril de 2009
$15 \mathrm{EM}, 36$.

16 EM, 36.

$17 \mathrm{EM}, 38$.

$18 \mathrm{EM}, 38$.

19 Sobre la crítica de las ideas de Gaos en este punto, Cf. ASV, "Vida y filosofía en el exilio" en EM, 125 y "Mi trato con la poesía en el exilio", EM, 184.

20 ASV, "Del destierro al transtierro" (2000) en TD, 605.

21 ASV, EM, 113-115.

22 ASV, "Exilio y filosofía. La aportación de los exiliados españoles al filosofar hispanoamericano", en EM, 105-112.

23 En el primer viaje a México que hice para asistir al Congreso de Toluca a mediados de los años ochenta con Ana Lucas y Manuel Reyes Mate, compañeros de la UNED, tuvimos la ocasión de compartir varias conversaciones con Nicol e incluso de grabar, junto con Ana Lucas, con él dos programas de radio para Revista de Filosofia, programa radiofónico de la radio educativa de la UNED. En dichas conversaciones recordó su participación en la guerra en el frente de Cataluña, donde perteneció al servicio de inteligencia dedicado a escuchar las conversaciones de los pilotos franquistas que bombardeaban Barcelona a partir de sus bases en Mallorca. Igualmente nos habló de un informe que realizó sobre el cañón 88 alemán de doble uso, antiaéreo y antitanque, que envío a lo servicios secretos británicos sin encontrar eco alguno. Posteriormente dicho cañón en El Alamein destrozó los tanques británicos y Nicol decía si los ingleses hubieran hecho caso del informe que les envió un oscuro profesor español otra suerte hubieran tenido. Esta anécdota la traigo a colación para destacar que Nicol era un hombre con un fuerte compromiso versario del exilio en México" en EM, 31-33 y "Del destierro al transtierro" en TD, 602-604. 
con su patria y los ideales democráticos y con una fuerte preocupación por las cosas públicas.

24 Cf. ASV, "Palabras de reconocimiento a Eduardo Nicol", en EM, 160-162.

25 Cf. ASV, "El corto y fecundo exilio de Joaquín Xirau", en EM, 167-168.

\section{BIBLIOGRAFÍA}

Ana Lucas, "Adolfo Sánchez Vázquez: vida y obra" en EPF, 219-262.
González, J.; Pereira, C. y Vargas, G. (eds.) (1985): PRAXIS Y Filosofía. Ensayos en homenaje a Adolfo Sánchez Vázquez, Grijalbo, México.

Martínez, F. J. (2003): "La filosofía de la praxis de Adolfo Sánchez Vázquez", Prólogo a A. Sánchez Vázquez, Filosofía de la praxis, Siglo XXI, México, pp. 9-17.

Sánchez Vázquez, Escritos de política y filosofía, (EPF), Ayuso, FIM, Madrid, 1987,

- (1997): Del exilio en México. Recuerdos y reflexiones, (EM), Grijalbo, México.
- (2003): A tiempo y destiempo (TD), FCE, México.

- (2007): Creación, estética filosofía politica (CEFP), Ed. Complutense, Madrid, 2007.

Vargas, G. (1990): "La aportación de Adolfo Sánchez Vázquez a la filosofía de Latinoamérica", en ¿Qué hacer con la filosofía en América latina?, UAM, México, pp. 167-178.

- (2005): Esbozo histórico de la filosofía en México (siglo XX y otros ensayos, UANL, Monterrey. 